\title{
A New $\alpha$-Pyrone Derivative, 6-[(E)-Hept-1-enyl]- $\alpha$-pyrone, with Tyrosinase Inhibitory Activity from a Marine Isolate of the Fungus Botrytis
}

\author{
Dahai Zhang, ${ }^{*}$ Xianguo Li, ${ }^{\ddagger}$ Jung Sook Kang, Hong Dae Choi," and Byeng Wha Son ${ }^{\ddagger}$, \\ Department of Chemistry, Pukvong National Lniversity, Busan 608-737, Korea. E-mail: sonbwapknuackr \\ -College of Chemistry \& Chemical Engineering. Ocean University of China, Oingdao 266003, $P$. R. China \\ $\$$ College of Dentistr, Pusan National Universit, Busan 602-739, Korea \\ "Department of Chemistry. Dongeu Chiversitw, Busan 614-714, Korea \\ Recened January 5, 2007
}

Key Words : Marine fungus Botrytis sp.. 6-[(E)-Hept-I-enyl $]$ - $\alpha$-pyrone. 6-[(E)-Pent-I-enỵl]- $\alpha$-py rone. 4-Hỵdroxyphenethyl alcohol. Tyrosinase inhibitory activity

Microorganisms such as bacteria. fungi. and blue-green algae have proven to be a rich source of new biologically active secondary metabolites. ${ }^{1}$ Marine nicroorganisms. particularly marine fungi. have recently drawn much attention as an important source of biologically active secondary metabolites. $^{2}$ Anong marine fungi. those living in association with marine algae are promising sources of novel natural products due to their unique ecological niche. The association between algae and fungi appears to be highly developed since nearly one-third of all higher marine fungi described are namely algicolous or algae-associated organisms. ${ }^{3}$ Recently, marine-derived fungi have yielded unique biologically active metabolites. such as myrothenones. ${ }^{4}$ gliotoxin derivatives. ${ }^{5}$ and asperflavin ribofuranoside, ${ }^{5}$ suggesting that these organisms would be valuable producers of potential therapentic agents

As part of our search for bioactive substances from marine microorganism, ${ }^{5}$ the fungus was studied because the broth extract showed potent tyrosinase inhibitory activity. ${ }^{7}$ In order to identify the active compounds, the broth was further separated into single ones. Careful bioassay-guided fractionations resulted in isolation of a new $\alpha$-pyrone derivative, 6$[(E)$-hept-1-enyl]- $\alpha$-pyrone (1), and two known compounds. 6-[(E)-pent-1-enyl]- $\alpha$-pyrone $(2)^{8}$ and 4-hydroxyphenethyl alcohol $(3)^{9}$ from the marine isolate of fungus Botrytis sp. We herein report the isolation and structural elucidation of compounds 1-3.

6-[(E)-Hept-1-enyl]- $\alpha$-pyrone (1) was a colorless oil isolated from the broth extract. A molecular formula of $\mathrm{C}_{12} \mathrm{H}_{16} \mathrm{O}$. which gave five degrees of unsaturation. was

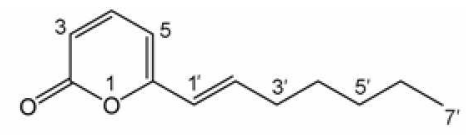

6- $[(E)$-hept-1-enyl]- $\alpha$-pyrone (1)

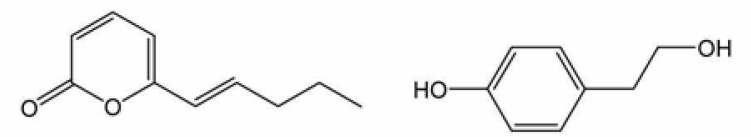

6-[(E)-pent-1-enyl]- $\alpha$-pyrone (2) 4-hydroxyphenethyl alcohol (3) established by HREIMS and ${ }^{13} \mathrm{C}$ NMR methods. The ${ }^{1} \mathrm{H}$ and ${ }^{13} \mathrm{C}$ NMR spectra. including DEPT, showed one methyl, four $\mathrm{sp}^{3}$ methylenes, five $\mathrm{sp}^{2}$ methines, and two $\mathrm{sp}^{2}$ oxygenated quatenary carbons. Detailed analyses of the ${ }^{1} \mathrm{H}$ and ${ }^{13} \mathrm{C}$ NMR spectra of 1. including the results from COSY and TOCSY experiments, suggest the presence of $(E)$-hept-1enyl group and 6-substituted $\alpha$-pyrone, which were further supported by the fragment ion, $m z 95\left[\mathrm{M}-\mathrm{C}_{7} \mathrm{H}_{13}\right]^{+}$. in the mass spectrum and IR data $\left(1735.1648,1541 \mathrm{~cm}^{-1}\right)$, respectively. The comection of functional groups in $\mathbf{1}$ was achieved on the basis of HMBC Diagnostic HMBC correlations. from $\mathrm{H}-5$ to $\mathrm{C}-\mathrm{I}^{\prime}$. from $\mathrm{H}-\mathrm{I}^{\prime}$ to $\mathrm{C}-5$. $\mathrm{C}-6$ and $\mathrm{C}$ 3', and from $\mathrm{H}-2$ ' to $\mathrm{C}-6, \mathrm{C}-3^{\prime}$ and $\mathrm{C}-4$ ', showed the connection of $\mathrm{C} 6-\mathrm{Cl}^{\prime}$ in 1 . The coupling constant between $\mathrm{H}-\mathrm{I}^{\prime}$ and $\mathrm{H}-2^{\prime}\left(J_{\mathrm{H} \mathrm{I}^{\prime}-\mathrm{H}^{\prime}}=15.5 \mathrm{~Hz}\right)$ was critical in establishing the $(E)$ geometry of double bond of compound 1 . On the basis of all the foregoing evidence, we propose that the structure of compound 1 is $6-[(E)$-hept-1-enyl]- $\alpha$-pyrone.

The known compounds 2 and $\mathbf{3}$ were identified by spectroscopic analysis ( ${ }^{1} \mathrm{H}$ and ${ }^{13} \mathrm{C}$ NMR. and LREIMS) and comparison to literature data. ${ }^{8,9}$

Compound 1 exhibited a tyrosinase inhibitory activity with IC 5 , value of $4.5 \mu \mathrm{M}$, which is more active than kojic acid (IC $5(1.15 .5 \mu \mathrm{M}$ ) currently being used as a functional personal-care compound. But compound 2 showed a weak tyrosinase inhibitory activity with $\mathrm{IC}_{50}$ value of $155.5 \mu \mathrm{M}$.

\section{Experimental Section}

General. UV/visible spectra were measured on a Hitachi U-2001 UV/Vis spectrometer. IR spectra were recorded on a Bruker FT-IR model IFS-88 spectrometer. ${ }^{1} \mathrm{H}(400 \mathrm{MHz})$ and ${ }^{13} \mathrm{C}$ NMR $(100 \mathrm{MHz})$ spectra were obtained on a JEOL JNM-ECP 400 NMR spectrometer. using TMS or solvent peaks ( $\delta 2.50 \mathrm{in}{ }^{1} \mathrm{H}$ and $\delta 39.5 \mathrm{in}{ }^{13} \mathrm{C}$ NMR) as reference standard. MS spectra were obtained on a JEOL JMS-700 spectrometer.

Fungal Isolation and Culture. The fungal strain was isolated from the surface of the marine red alga Hyalosiphonia caespitosa collected at Dadaepo, Busan in 2004, and identified as a Botmtis sp. (Family: Sclerotiniaceae) based 
Table 1. NMR Spectroscopic Data (400 MHz, DMSO- $d_{0}$ ) for $6-$ $[(E)$-hept-1-enyl]- $\alpha$-pyrone $(1)$

\begin{tabular}{ccl}
\hline & \multicolumn{3}{c}{$6-[(E)$-hept-l-enyl]-(x-pyrone $(1)$} \\
\hline position & \multicolumn{1}{c}{$\delta_{t, \text { mult }}$} & \multicolumn{1}{c}{$\delta_{H,}(\mathrm{~J}$ in Hz$)$} \\
\hline 2 & $160.8, \mathrm{qC}$ & \\
3 & $113.2, \mathrm{CH}$ & $6.18, \mathrm{~d}(9.0)$ \\
4 & $145.0, \mathrm{CH}$ & $7.52, \mathrm{dd}(9.0,6.7)$ \\
5 & $103.7, \mathrm{CH}$ & $6.29, \mathrm{~d}(6.7)$ \\
6 & $158.8, \mathrm{qC}$ & \\
$1^{\prime}$ & $122.0, \mathrm{CH}$ & $6.20, \mathrm{~d}(15.5)$ \\
$2^{\prime}$ & $138.1, \mathrm{CH}$ & $6.50, \mathrm{dt}(15.5,7.0)$ \\
$3^{\prime}$ & $31.9, \mathrm{CH}_{2}$ & $2.19, \mathrm{dt}(7.0,7.2)$ \\
$4^{\prime}$ & $27.7, \mathrm{CH}_{2}$ & $1.42, \mathrm{tt}(7.2,7.2)$ \\
$5^{\prime}$ & $30.7, \mathrm{CH}_{2}$ & $1.28, \mathrm{~m}$ \\
$6^{\prime}$ & $21.8, \mathrm{CH}_{2}$ & $1.28, \mathrm{~m}$ \\
$7^{\prime}$ & $13.8, \mathrm{CH}_{2}$ & $0.86, \mathrm{t}(7.0)$ \\
\hline
\end{tabular}

on fatty acid methyl ester analysis (Korean Culture Center of Microorganismıs. Seoul. Korea, sumilarity index of 0.62). A voucher specimen is deposited at Pukyong National University with the code MFB604. The fungus was cultured (20 L) for three weeks (static) at $29^{\circ} \mathrm{C}$ in SWS medium consisted of soytone $(0.1 \%)$. soluble starch $(1.0 \%)$. and seawater $(100 \%)$.

Extraction and Isolation. The mycelium and broth were separated by filtration. The filtered broth was extracted with EtOAc to afford broth extract $(0.9 \mathrm{~g})$. which was subjected to Si gel flash chromatography. Elution was performed with $n$-hexane-EtOAc (stepwise, $0-100 \%$ EtOAc) to yield four fractions. Fractions 2 and 3 on medium pressure liquid chromatography (MPLC) (ODS) by elution with $\mathrm{H}_{2} \mathrm{O}$ $\mathrm{MeOH}$ (from 1:1 to 1:5) afforded crude compounds 1 and 2. and 3, respectively. which were further purified by HPLC (YMC ODS-A) utilizing a $30 \mathrm{~min}$ gradient program of $50 \%$ to $100 \% \mathrm{MeOH}$ in $\mathrm{H}_{2} \mathrm{O}$ to furnish $1(10.2 \mathrm{mg}) .2(1.5 \mathrm{mg})$. and $\mathbf{3}(3.5 \mathrm{mg})$, respectively:

$6-[(E)$-Hept-l-enyl]- $\alpha$-pyrone (1) was obtained as a colorless oil: UV (MeOH) $\lambda_{\text {max }}(\log \varepsilon) 336$ (6.1) nm: IR (neat) $v_{\text {max }} 2932,2928.2857 .1735 .1648,1541,1459.1223 .1097$. $793 \mathrm{~cm}^{-1} ;{ }^{1} \mathrm{H}$ and ${ }^{13} \mathrm{C}$ NMR, see Table 1; EIMS $m z 192$ $\left[\mathrm{M}^{-}(45) .123(100) .110(39), 107\right.$ (37). $95\left[\mathrm{M}-\mathrm{C}_{7} \mathrm{H}_{33}\right]^{-}$ (47). 79 (38); HREIMS $m z 192.1149$ (calcd for $\mathrm{C}_{12} \mathrm{H}_{16} \mathrm{O}_{2}$, $192.1150)$

6-[(E)-Pent-1-enyl]- $\alpha$-pyrone (2) and 4-hy droxyphenethyl alcohol (3) were obtained as a colorless oil. and showed spectral data virtually identical to those reported in the literature. ${ }^{8,9}$

Acknowledgment. This work was supported by a grant from MarineBio2l. Ministry of Maritime Affairs and Fisheries, Korea. Mass spectral data were kindly provided by the Korea Basic Science Institute.

\section{References}

1. Lee. H. B.: Oh. H. Bull Korew Chem. Soc. 2006. 27. 779-782. and reference cited therein.

2. Blutt. J. W.: Copp. B. R.: Munro. M. H. G.: Northeote. P. T.: Prinsep. M. R. Nat. Prod. Rep. 2006. 23. 26-78.

3. Kohlmeyer. J; Kohlmeyer, E. In Harine Hycolog? The Higher Fungi: Academic Press: New York. 1979; pp 54-69.

4. Li. X; Kim. M. K.; Lee. U.; Kim. S.-K.: Kang. J. S.; Choi. H. D: Son. B. W. Chem. Phom. Bull. 2005. $53.453-455$

5. Li. X:: Kim. S.-K.: Nam1. K. W.: Kang. J. S.: Choi. H. D.: Son1. B. W. J. Antibiot 2006. 59. 248-250.

6. Li. Y.: Li. X; Lee. U; Kang, J. S.: Choi. H. D: Son, B. W. Chem Pham Bull 2006, 54. $882-883$.

7. Li. X.; Li, Y.: Jeong J. H.: Lee, K. T; Choi, H. D; Son, B. W. Kon J. Phamacogn. 2003. 3t. 138-141

8. Thibonnet. T.: Abarbri. M.: Parrain. T.-L:: Duchene. A. J. Org. Chent 2002. 67. 3941-3944.

9. Pouchert, C. J.: Behnke, J. In The Aldrich Library of ${ }^{\prime 3} \mathrm{C}$ and ${ }^{\prime} \mathrm{H}$ FT MR Spectra, lst ed:; Aldrich Chemical Company. Ine: U.S.A., 1993: Vol. 2, p 409. 